\title{
TÉCNICAS DE CONSERVAÇÃO NO COMBATE À EROSÃO DO SOLO: ESTUDO DA EFICIÊNCIA DO MURO DE GABIÕES NO BAIRRO NACIONAL, CONTAGEM/MINAS GERAIS
}

\author{
Malena Silva Nunes ${ }^{(a)}$, João Pedro martins da Cruz $^{(\mathrm{b})}$, Iara Lana Santana ${ }^{(\mathrm{c})}$, Ricardo José Gontijo \\ Azevedo $^{(\mathrm{d})}$ \\ (a) Departamento de Geografia e História, Centro Federal de Educação Técnica e Tecnológica de Minas Gerais \\ (CEFET-MG) / Instituto de Geociências, Universidade Federal de Minas Gerais (UFMG), \\ malenanunes@deii.cefetmg.br \\ (b) Centro Federal de Educação Técnica e Tecnológica de Minas Gerais (CEFET-MG), joao.pedro.10m@gmail.com \\ (c) Centro Federal de Educação Técnica e Tecnológica de Minas Gerais (CEFET-MG), iaralana46@ gmail.com \\ (d) Departamento de Geografia e História, Centro Federal de Educação Técnica e Tecnológica de Minas Gerais \\ (CEFET-MG), ricardogeop@yahoo.com.br
}

\section{Eixo: GEOGRAFIA FÍSICA E DESASTRES NATURAIS}

\begin{abstract}
RESUMO
O presente estudo é resultado de atividades desenvolvidas na disciplina de Conservação dos Solos, do curso técnico em Meio Ambiente do CEFET-MG. O estudo de caso apresentado neste trabalho teve como objetivo avaliar, através de análises qualitativas e entrevistas com a população afetada por processos erosivos, a eficiência da técnica de conservação do solo denominada muro de gabiões. A análise foi realizada no Bairro Nacional, no município de Contagem, localizado na Região Metropolitana de Belo Horizonte (RMBH), Minas Gerais. A técnica empregada se mostrou eficaz uma vez que minimizou os problemas associados a processos erosivos que ocorriam principalmente nos períodos chuvosos.
\end{abstract}

Palavras chave: erosão; técnicas de conservação; muro de gabiões.

\section{Introdução}

A erosão, processo de desagregação e remoção do solo ou fragmentos e partículas de rochas, pela ação combinada da gravidade com a água, vento e gelo, é um fenômeno natural que, muitas vezes, é agravado pela ação antrópica. Fatores como a chuva, o relevo, as características do solo, o desmatamento, as atividades agropecuárias e a expansão urbana influenciam diretamente na ocorrência de processos erosivos (BERTONCINI, 2008).

A erosão pode ser dividida em três etapas, sendo elas, respectivamente, desgaste do solo, transporte de sedimentos e deposição dos mesmos (BIGARELLA, 2003). Dessa forma, é responsável por desencadear diversos impactos de caráter ambiental e socioeconômico, tais como a poluição e o assoreamento de cursos hídricos, a morte de vegetação, a ocorrência de enchentes, a desertificação e a degradação de 
paisagens. Tendo em vista os impactos negativos associados aos processos erosivos, é fundamental o estudo e a execução de técnicas que visem a prevenção ou minimização dos mesmos. Práticas como aração, plantio em curvas de nível, terraceamento, estruturas para desvio e infiltração da água, construções de muros de contenção e taludes são exemplos de técnicas que podem auxiliar no combate adequado à erosão (NUNES, 2016).

A técnica de contenção, objeto de estudo deste trabalho, é o muro de gabiões, que consiste em uma estrutura metálica confeccionada com malha hexagonal de dupla torção. Tal estrutura forma uma espécie de caixa, que é preenchida com pedras (JÚNIO e VIANA, 2016). O muro de gabiões pode ser classificado, portanto, como uma técnica de caráter mecânico, uma vez que modifica a estrutura do local em que ocorre a implantação. Os gabiões são aplicados, portanto, como muros de contenção, a fim de proteger margens de cursos d'água, controlar a erosão e auxiliar obras de emergência (BARROS, 2008).

A técnica apresentada possui diversas vantagens, do ponto de vista técnico e econômico. Apresentam facilidade para confecção e não exigem mão de obra especializada, tornando viável sua implantação mesmo em locais que recebem menos invetsimentos. Outra característica intereesante do muro de gabiões é que sua composição não constitui obstáculo impermeável para infiltração e percolação, permitindo, assim, passagem de água e o crescimento de vegetação. Além disso, o muro de gabiões é prático e versátil, pois possui grande flexibilidade e permite deslocamentos e deformações (BARROS, 2008).

Para garantir a efetividade da estrutura são necessários alguns cuidados: regularização e nivelamento do terreno de fundação, boa arrumação das pedras e colocação de elemento de transição entre os gabiões e o material a ser contido. Em áreas urbanas, sujeitas a vandalismo, deve-se revestir a face externa com argamassa. Apresentam ainda mais resistência e durabilidade quando possuem revestimentos especiais. (WOLNEY, 2014).

\section{Caracterização da área}

A área de estudo está situada no bairro Nacional, no município de Contagem, que compõe a Região Metropolitana de Belo Horizonte (Figura 1). É demarcada pela presença do córrego Gangorra, afluente do córrego Bom Jesus, e por ter seu entorno ocupado por moradias. A Figura 1 representa a área analisada. 


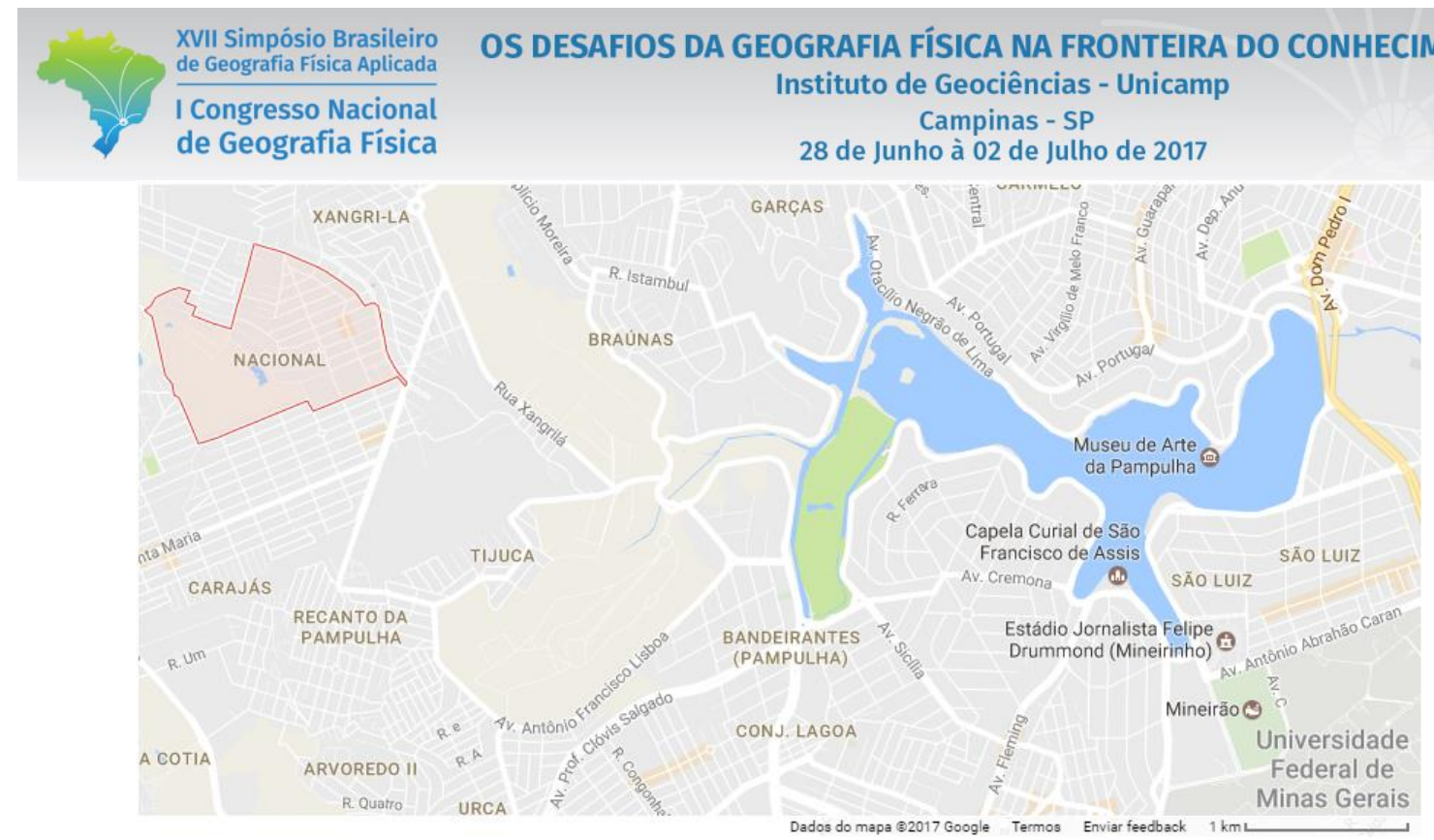

Figura 1 - Localização do bairro Nacional, em Contagem, próximo ao limite municipal de Belo Horizonte.

Fonte: Google Maps, 2017.

Devido aos prejuízos, materiais e imateriais, causados pelos processos erosivos intensificados nos períodos chuvosos, a prefeitura de Contagem implantou, há aproximadamente três anos, o muro de gabiões no local. Estes foram instalados nas encostas e no fundo do curso hídrico estudado, visando a contenção da erosão e do assoreamento na área (Figuras 2 e 3).

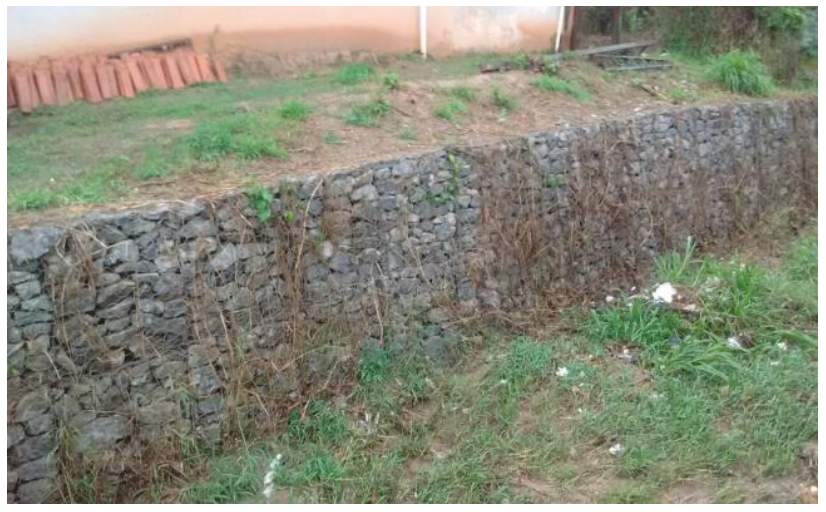

Figura 2 - Margem esquerda do córrego estudado.

Fonte: Acervo pessoal.

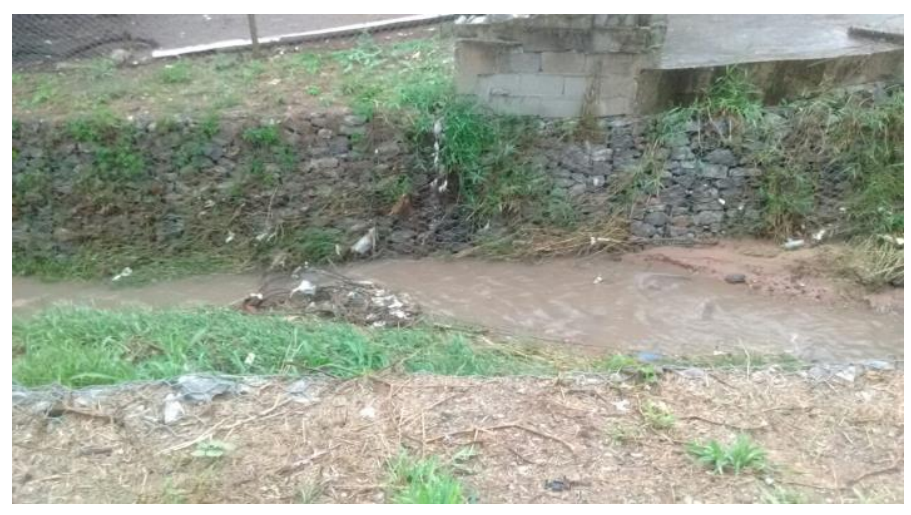

Figura 3 - Margem direita do córrego estudado.

Fonte: Acervo pessoal.

Ressalta-se que antes da construção do muro de gabiões uma das três habitações sofria constantes danos advindos dos processos erosivos recorrentes, que, em associação com o excesso de água da chuva, inundava a moradia. Esse quadro levou a proprietária da residência a realizar uma obra de direcionamento da água da chuva (Figura 4). 


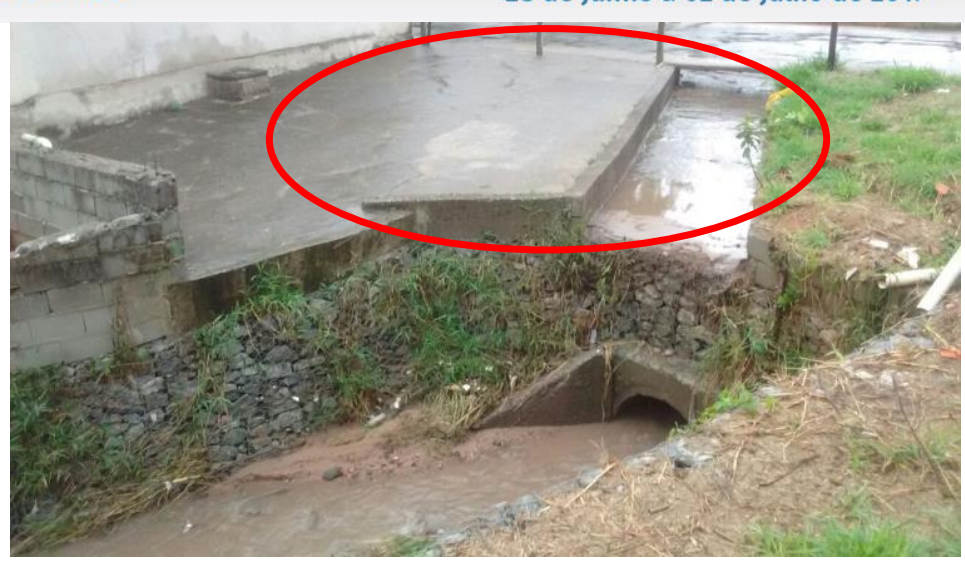

Figura 4 - Obra de direcionamento da água da chuva, junto ao muro de gabiões.

Fonte: Acervo pessoal

\section{Procedimentos metodológicos}

Para realizar a identificação e a análise da eficiência do muro de gabiões implantado no bairro Nacional, executou-se levantamentos de caráter qualitativo, por meio de visita ao local, seguida de entrevistas informais com os moradores do entorno. Também foram realizadas pesquisas aos referenciais teóricos acerca da técnica empregada na área. Algumas fotografias foram capturadas a fim de inferir confiabilidade ao estudo. Além disso, a efetividade da técnica foi observada ao longo dos meses de Novembro e Dezembro, que, de acordo com dados obtidos juntos à Estação Meteorológica da Pampulha (ClimaTempo), a mais próxima da área de estudo, apresentou $213 \mathrm{~mm}$ e 313,6 mm de chuva, respectivamente.

\section{Resultados e discussão}

De acordo com as entrevistas e com a observação da área nos meses de Novembro e Dezembro pode-se afirmar que a partir da implantação da técnica os problemas encontrados na área foram mitigados. O muro de gabiões tem apresentado melhorias para a região, uma vez que, de fato, controlou os processos erosivos verificados anteriormente no local. Sendo assim, além de realizar uma alteração no meio físico, a técnica favoreceu os moradores da área, prevenindo possíveis prejuízos ocasionados pelas consequências da erosão e do assoreamento, como os riscos constantes de enchentes.

Os benefícios propiciados pela prática conservacionista, já esperados pela implantação da técnica, foram relatados e confirmados pela população situada no entorno da área. De acordo com relatos dos moradores do entorno os desmoronamentos constantes no período chuvoso não ocorreram após a instalação da técnica. 


\section{Considerações}

A constatação dos efeitos positivos para a população após a instalação do muro de gabiões evidenciou a importância do controle dos processos erosivos, bem como os impactos gerados por sua ausência em áreas susceptíveis. A identificação e o estudo da técnica de conservação proporcionou melhor entendimento acerca de seu funcionamento e ampliou os conhecimentos acerca de técnicas conservacionistas. Além disso, destaca-se a importância da população no monitoramento da efetividade da mesma.

Considera-se fundamental a continuidade e ampliação de estudos que avaliem a eficiência da aplicação de técnicas de conservação do solo em áreas urbanas, já que envolvem a possibilidade de ocorrência de danos e perdas materiais e de vidas. Logo, estão diretamente associadas ao planejamento urbano e ambiental ideais e adequados para a manutenção sadia da relação sociedade/natureza.

Salienta-se, ainda, que este estudo é resultado de trabalhos realizados na disciplina de Conservação dos Solos, do curso técnico em Meio Ambiente do CEFET-MG. Dessa forma, pode-se analisar, na prática, conteúdos até então vistos apenas em sala de aula, contribuindo, portanto, para a aplicação técnica, objetivo base da educação técnica e tecnológica.

\section{Bibliografia}

BARROS, P. L. A.Obras de contenção: Manual Técnino. Maccaferri,Recife,p.09-16,jun.2008. Disponível em: http://www.aecweb.com.br/cls/catalogos/maccafe rri/obras_de_contencao_opt.pdf $>$.Acesso em: 14nov.2016

BERTONCINI, E. I. Controles de Erosão. Revista de Fundações \& Obras Geotécnicas, São Paulo, p.72-83, jun. 2008.Disponível em: < http://abge.org.br/uploads/arquivos/archivoseccion_244_emfococontroledeeros.pdf>. Ace sso em: 15 nov. 2016.

BIGARELla, J. J. Estrutura e Origem das Paisagens Tropicais e Subtropicais. Volume 3. Editora UFSC, Florianópolis, 2003.

CLIMATEMPO. Climatologia: Contagem - MG. Contagem, dez. 2016. Disponível em: <http://www.climatempo.com.br/climatologia/130/contagem-mg>. Acesso em: 15 jan. 2017.

JÚNIO, A. M. M., VIANA, P. M. F. Análise da estabilidade externa de um muro de gabião próximo ao viaduto marginal botafogo. (In): Revista Construindo, v. 08, n. 02, jul/dez 2016.

NUNES, M.S. Processos erosivos: fatores causadores, consequências ambientais e formas de manejo. CEFET MG. 2016. 


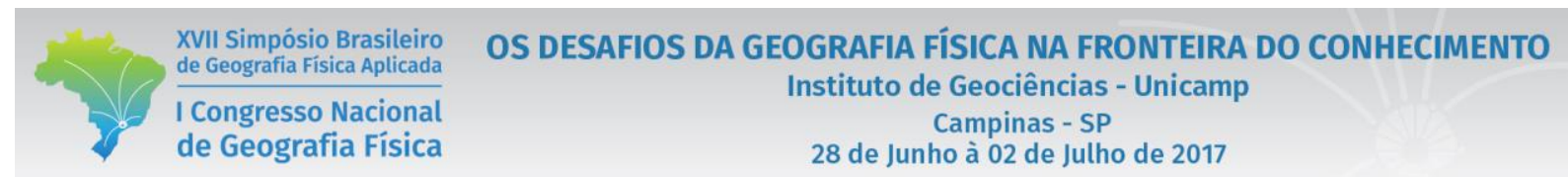

WOLNEY, D. Sistema de Contenção Terramesh. Revista de Fundações \& Obras. Geotécnicas. São Paulo. 1-12 p. Jun/2014. 